\title{
Demand Side Management in District Heating Systems
}

\author{
Fredrik Wernstedt \\ NODA Intelligent Systems AB \\ Drottninggatan 5, 374 35, Karlshamn, \\ Sweden \\ +46-(0)735-309501 \\ fredrik.wernstedt@noda.se
}

\author{
Paul Davidsson \\ School of Engineering, \\ Blekinge Institute of Technology \\ 372 25, Ronneby, Sweden \\ +46-(0)457-385841 \\ paul.davidsson@bth.se
}

\author{
Christian Johansson \\ NODA Intelligent Systems AB \\ Drottninggatan 5, 374 35, Karlshamn, \\ Sweden \\ +46-(0)735-309502 \\ christian.johansson@noda.se
}

\begin{abstract}
This paper describes a multiagent system that has made the voyage from research project to commercialised product. The purpose for the multiagent system is to dynamically control a system so that the load of the system is below certain threshold values without reduction of quality of service and by that, to avoid the usage of top load production sources and to reduce energy consumption. The fundamental idea behind the system is that a large number of small local decisions taken all in all have great impact on the overall system performance. A field-test as well as a return of investment analysis are presented.
\end{abstract}

\section{Categories and Subject Descriptors}

C.3. [Special-purpose and application-based systems]: Process control systems, Real-time and embedded systems.

\section{General Terms}

Management, Performance, Economics, Reliability.

\section{Keywords}

Agent-based deployed applications.

\section{INTRODUCTION}

This paper describes a multiagent system that dynamically controls District Heating Systems (DHS) so that the load of the system is kept below certain threshold values without reducing of quality of service provided to the customers. The purpose is to avoid the usage of top load production sources (which often uses fossil fuel) and to reduce energy consumption. The fundamental idea behind the system is that a large number of small local decisions together have great impact on the overall system performance.

This venture started as a research project in 1999 as a collaboration effort between Cetetherm (now Alfa Laval), and Blekinge Institute of Technology. The project has since evolved

\footnotetext{
Permission to make digital or hard copies of all or part of this work for personal or classroom use is granted without fee provided that copies are not made or distributed for profit or commercial advantage and that copies bear this notice and the full citation on the first page. To copy otherwise, or republish, to post on servers or to redistribute to lists, requires prior specific permission and/or a fee.

AAMAS’07, May 14-18, 2007, Honolulu, Hawai'i, USA.

Copyright 2007 IFAAMAS.
}

throughout the last few years into this current commercial project, an effort within which the spin-off company NODA Intelligent Systems AB was founded in early 2005. A field-test has just been completed and is reported Section 4. The main focus was to validate the system from a technical standpoint. However, since our intent is to commercialise the system, the economical benefits were equally important to investigate.

\subsection{Background}

The basic idea behind district heating is to use local heat production plants to produce hot water. This water is then distributed by using one or more pumps at approximately $1-3 \mathrm{~m} / \mathrm{s}$ through pipes to the customers where Heat Exchange Systems (HES) are used to exchange heat from the primary flow of the distribution pipes to the secondary flows of the building. The secondary flows are used for heating both tap water and the building itself. In large cities district heating networks tend to be very complex, including tens of thousands of substations and hundreds of kilometers of distribution pipes with distribution times up to 24 hours.

The energy load of any DHS is subject to large variations due to the fluctuating demands of customers. The energy load is mainly divided between the rather slow process of space heating and the fast process of domestic hot tap water consumption. A DHS must be capable of meeting all such fluctuating energy demands.

Optimisation of DHS has traditionally focused on production plants and distribution systems. However, in the last ten years, consumer heating systems (HES) have received increased attention. The product development of HES has changed from focusing on the component (sub optimisation) to focusing on the interaction of the components (system optimisation) [2]. HES, as the heat load source of a DHS, determine the operation of the total DHS. Yet it is unusual that the operation of HES can be monitored or controlled by the DHS operator. The operation strategies of the DHS are therefore limited to providing sufficiently high temperature and pressure to all customers, without any possibility of actually optimising the system as a whole.

Load control HES can either be achieved directly by remote control of individual HES or indirectly by usage of various tariffs. Indirect load control is widely used and has primarily been implemented by the usage of flow tariffs, i.e., customers are charged according to the flow in comparison to a reference value for the flow. Direct load control is very uncommon but there exists a few attempts, e.g., a centralised load control system that 
was studied by Österlind [1]. Österlind used a one-way communication link on the electricity network to manipulate the outdoor temperature meters of individual HES. By this communication link he was able to manipulate and control the space heating of the connected buildings. The study confirmed earlier theories of centralised load control and showed that it is relatively easy to achieve robustness against shortage situations in DHS. However, the system did not consider, e.g., fairness and the quality of service (QoS) delivered to the individual consumer. Österlind also concluded that two-way communication was a minimum requirement for an operational system [3]. Two-way communication systems for $\mathrm{DH}$ substations are currently at a relatively early stage of development. However, as hardware is becoming available focus should now be on how to use the data/information and how to achieve savings [4].

Energy is not an end in itself; instead it is a means to provide a number of services. Businesses and households view energy as an input, an expense of doing business or maintaining a home. They are less concerned with how many kilowatt hours they purchase than with the services that the energy provides, e.g., space heating. This relationship provides the basis of demand-side management (DSM). DSM can be defined as "The planning and implementation of strategies designed to encourage consumers to improve energy efficiency, reduce energy costs, change the time of usage or promote the use of a different energy source" [5]. DSM strategies try to reduce the peak load and change the shape of the load profile through the techniques of peak clipping, load shifting and energy conservation. DSM activities should bring the demand and supply closer to a perceived optimum. Correctly implemented, DSM strategies can reduce energy consumption with the associated financial and environmental benefits. The idea behind energy efficiency is quite simple; if people consume less energy, there will be less emission of greenhouse gases as the result of less burning of fossil fuels in heat production plants. Energy efficiency technologies and practices can therefore play a significant role in reducing the threat of global climate change.

There is very little information and expertise available on DSM for DHS. Today, there is a growing interest, but while DSM has become a standard technique for the electricity market $[6,7,8,9,10]$, it is still in the early stages when considering DHS [11]. The goal of DSM is to be able to control the heat load at an overall system level rather than to even out the consumption of individual HES. Sipilä and Kärkkäinen [12] study the dynamics and potential for DSM in individual buildings connected to a DHS and showed that the maximum heat load of a building can temporarily (during 2-3 hours) be reduced as much as $25 \%$ on average. Not once during the test conditions did the room temperature shift more than 2 degrees. In simulation experiments, Noren and Pyrko [13] show that the most successful load control strategy for electricity heated commercial buildings is load reductions of about $40-50 \%$ during longer time periods (4h). Stronger load reductions during shorter periods can cause recovery loads higher than the previous maximum demand. The results show that it is possible to move the maximum load several hours in time without discomfort for the customers. The possible reductions in each individual HES indicate that if this kind of measures would simultaneously be performed in a large number of buildings, the maximum load of a DHS can be lowered substantially.
The potential of DSM in DHS is mainly claimed to consist of; lower production costs, reduced usage of fossil fuel, running production units in the most efficient states, increasing the net profit of back-pressure Combined Heating and Power (CHP) electricity sales, handling capacity issues in existing DHS, dimensioning production capacity for a lower effect/reserve alternatively with maintained dimensioning increasing the number of consumers in a particular size DHS.

We present results from a project that has made the voyage from research project to commercial product. Our focus is the trade-off between system optimality and QoS for each connected customer, where our goal is to provide as high QoS as possible while using the production resources in an environmentally and financially optimal way.

\section{MAS ARCHITECTURE}

The availability of small high-capacity computational units has lead to an increasing decentralisation within automation systems as well as a distribution of functionality into geographically dispersed devices. The possibility to connect these distributed units in a Local Area Network (LAN) promises highly dynamic systems. However, the problem of providing a suitable framework for coordinating the connected devices remains.

All buildings in a DHS are more or less unique when considering specific details of inhabitant preferences, household equipment, thermal characteristics, etc. To maintain a centralised model of each connected building in a large DHS with several thousands of consumers would be extremely challenging with respect to computation and communication. In fact, it is argued that when the complexity of a DHS reaches approximately 100 components and restrictions, the present computer and software technology is insufficient for finding an optimal operational strategy [14]. Since an optimal operational strategy is not practically achievable, a method based on some heuristic is needed to find a good-enough strategy. It is possible to perform completely distributed computation to generate an operational strategy. However, the computation would be limited by system knowledge, i.e., the distributed units would not have enough knowledge about the production to conclude the best operational strategy. If the performance degradation of a completely decentralised solution is too large and a completely centralised solution is too complex, a compromise will have to be found.

Due to the rising demand of automation of building services (heating, ventilation, and air-conditioning etc.) Siemens have developed the Saphir, an extendable I/O platform with an expansion slot for a communication card, suitable for equipment control. Access to sensor and actuator data is provided by a Rainbow communication card in the expansion slot.

The Saphir contains a database that continuously is updated with sensor data from the $\mathrm{I} / \mathrm{O}$ channels by a small real-time operating system, which is directly accessible from the Rainbow card. On the Rainbow card a small computational platform (a handheld PC) makes it possible to deploy software and by that providing the possibility to host an agent. Hence, an agent deployed on such a platform could potentially read all connected sensor input as well as send commands over the I/O channel to actuators on the hardware, e.g., valves on a heat exchanger. The Saphir platform and the Rainbow communication card have been integrated into a 
new type of HES, developed by Alfa Laval AB during the term of this research project.

We suggest using a semi-distributed approach. In this case each agent, embedded on a HES, is trying to optimise its own usage of the resources and coordinates with a base station in case there is a conflict. Our system has the following three types of agents:

- Consumer agents: (one for each consumer) which continuously (i) monitors and controls the local state and (ii) on request, participates on a cluster level market for partial system optimisation. The consumer agent is cooperative and has global responsibility to participate on the market for system optimisation by providing its true cost for participation in system wide optimisation.

- Cluster agents: (one for each cluster of consumers) which (i) maintains a market for partial system optimisation at a cluster level for consumer agents, and (ii) informs the producers agents of a selection of choices to achieve optimisation in the cluster, and (iii) propagates chosen optimisation actions from the producer agents to the consumer agents.

- Producer agents: (one for each producer) which continuously (i) monitor their local state and (ii) when necessary issues requests for optimisation of clusters to improve the local production state, and (iii) receives lists of possible optimising actions and informs clusters of chosen actions.

The general architecture of the MAS is shown in Figure 1

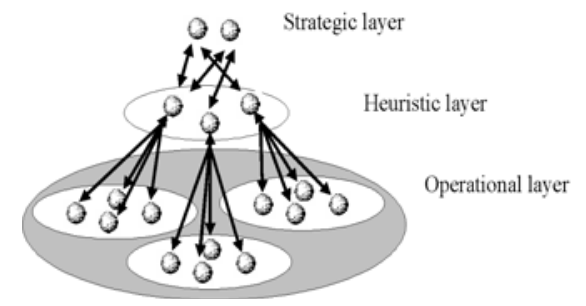

Figure 1. MAS Architecture.

The architecture consists of the three layers:

- $\quad$ Strategic layer: This layer consists of producer agents that have strategic goals, making decisions based on wide-area monitoring and control perspectives.

- Heuristic layer The cluster agents in this layer include heuristic knowledge to identify consumers willing to participate in optimisation. These agents also update the world model for the agents in the strategic layer.

- $\quad$ Operational layer: The consumer agents in this layer handle their individual hardware systems from a local point of view to achieve fast, consistent and informed control.

The abstract architecture, see Figure 2, for each individual agent is very similar to the Procedural Reasoning System (PRS) architecture [20].

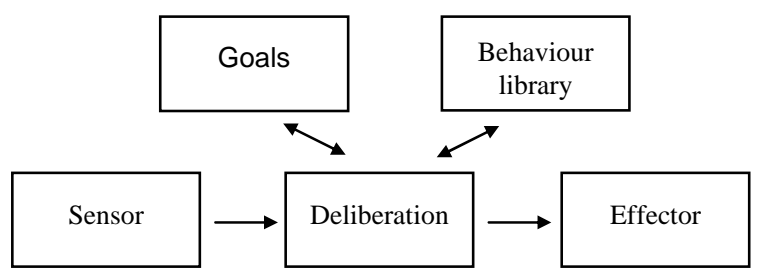

Figure 2. The abstract architecture of an agent.

The deliberator module is responsible for controlling all other components in order to pursue the goals of the agent. The deliberator also controls the interactions with other agents, i.e., it coordinates the sending and receiving of messages. The sensor component is the gateway to the perceptions of the external environment (including receiving messages). The effector component imposes changes to the external environment (including sending messages). The agent can through the effector component affect the external environment either indirectly by exchanging messages or directly through physical effectors (if it has physical effectors).

\section{AGENT BEHAVIOUR}

Our approach is based on the fact that DHS by nature are distributed both spatially and with respect to control. We utilize the naturally distributed control to fulfill a system level goal of making sure that the system load does not go above a threshold value and to ascertain that the water flow is as even as possible, i.e., to reduce sudden shifts in flow, while affecting the individual consumers as little as possible. Also, when we do affect the consumer we make sure to do it on their terms and in a fair way.

The aim of this method is an attempt to move demand away from the peak periods by reducing the energy destined for space heating. This reduction of demand will help to smooth out the energy supply profile and help obtain higher levels of efficiencies from the plants by trying to achieve a steady output instead of a load following the fluctuating domestic hot tap water regime. Reduction of the heat load of space is based on exploiting the thermal mass of the building and the secondary networks i.e. we do not restrict production of domestic hot tap water. These measures can reduce greenhouse gas emissions associated with using fossil fuels to meet those peak demands.

\subsection{Consumer Agent}

Cutting the load of customers will affect the service delivered, i.e., a constant reduction of space heating will eventually reduce the indoor temperature. The building heat storage capacity and isolation determines how quickly the temperature of the building adjusts to changes of the outdoor temperature. The time constant is defined as the time it takes for the indoor temperature to drop $63 \%$ of the difference between the outdoor temperature and the initial indoor temperature. Typical values for time constants are between 30-80 h for older buildings, but the range continues up to time constants of 5 days for highly isolated buildings, i.e., there exists buildings where we might shut down the space heating for quite some time without affecting the perceived QoS.

If the heating is not turned off completely, but just reduced, the operative time constant will change. For example, a supply of 
$50 \%$ of the required energy will increase the time constant by 2 , i.e., it will take twice the time to loose the indoor heat, i.e., if we do not completely shut down the heating and only reduce space heating during shorter time periods most buildings fall within the category of potential reductions without affecting QoS.

In Figure 3, we show how long time it takes for a building with a time constant of $60 \mathrm{~h}$ to cool down $3^{\circ} \mathrm{C}$ during different conditions regarding supplied energy. These values are calculated given an outdoor temperature of $-20^{\circ} \mathrm{C}$.

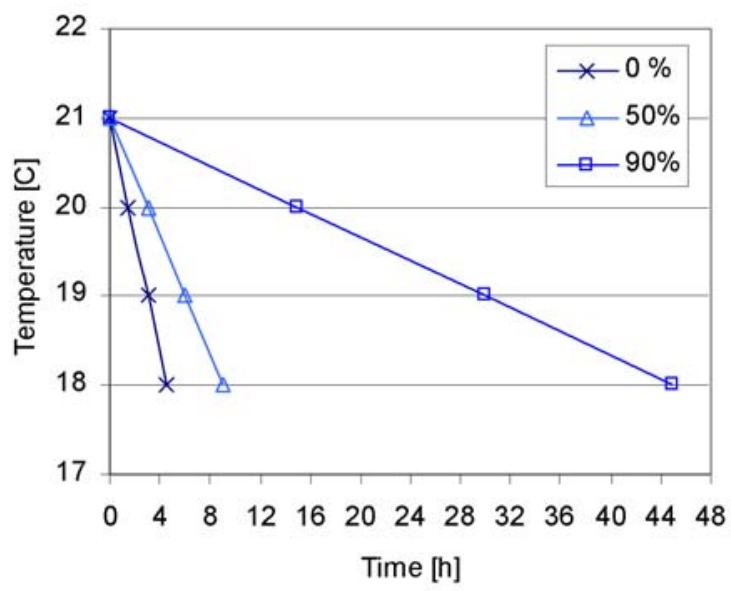

Figure 3. Example of the time it takes for a building to drop $3^{\circ} \mathrm{C}$ in temperature at different levels of energy supply.

The described thermal models for the indoor temperature are used in the utility function for calculating the cost for a consumer agent to participate in optimizing actions. Using this set of models assures that we get fair reductions in the network since buildings that have been reduced previously get higher costs (larger distance to reference temperature) for implementing new reductions and hence, some other building with closer distance to the reference temperature will have lower cost. Since this model considers the dynamic thermal state of individual buildings the building time constant will assure that buildings with different characteristics will be treated in a fair way and that reductions are spread evenly throughout the network of connected customers.

In order to maintain a given indoor temperature, the heat supplied to a building must equal the heat lost by the building. As the outdoor air temperature drops, the amount of heat lost from the building increases. The amount of heat that the space heating system can supply changes depending on the temperature of the supply water. As the temperature of the supply water increases, the amount of heat available from the space heating system increases. Each building has a heat curve to determine the set temperature for the space heating system, e.g., if the current outdoor temperature is $-5{ }^{\circ} \mathrm{C}$ the temperature in the space heating system should be, e.g., $44^{\circ} \mathrm{C}$ for a specific building. A reduction at a HES is performed by changing the temperature set value, e.g., a reduction of $10 \%$ on the set temperature of $44{ }^{\circ} \mathrm{C}$ would mean that the heat exchanger in the HES would heat the supply water in the space heating system to $39,6{ }^{\circ} \mathrm{C}$ instead of $44^{\circ} \mathrm{C}$. An issue with direct load reduction is that when the load reduction is released, the recovery load can get higher than the load would be without reductions and hence, the topload would not be reduced but rather increased. To reduce the recovery load, several different control strategies are possible [13]. However, all of these strategies will prolong the time it will take to restore the indoor temperature, so the recovery time must be considered for during calculation of cost for reduction at the customer side. The strategy we use to reduce the effect of recovery load is to restrict the rate of change on the set temperature for the secondary side in addition to letting the individual customer agents release their reductions randomly

\subsection{Producer Agent}

In a DHS, several different energy sources may be used for heating, e.g., waste energy, byproduct from industrial processes, geothermal reservoirs, otherwise combustion of fuels such as oil, natural gas etc. is used. When the demand from the customers is high, several heat producing units must normally be used, see Figure 4.

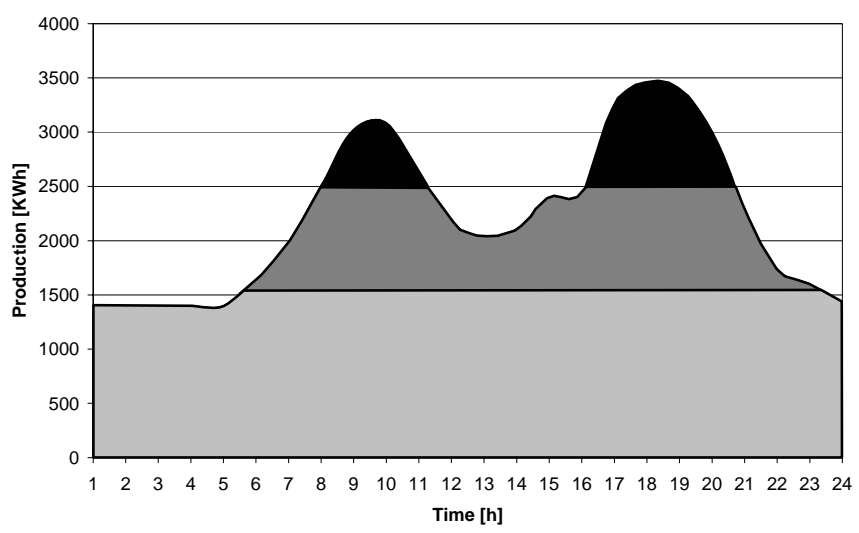

Figure 4. Different production sources may need to be used during the day depending on the load. The bottom field indicates usage of base production units (typically environmental friendly and cheap), the middle field indicate usage of intermediate production units (slightly more costly than the base units), and the top fields indicates usage of the more expensive top load production units (typically combustion of fossile fuel).

To avoid starting top load production units, the producer in our system issues requests for optimising actions when the heat load is between a lower and a higher threshold value. As the load is getting closer and closer to the higher threshold the intensity of requests increases. However, sufficient time needs to pass between requests, so that substations get enough time to carry out changes of valve positions. To decide that there is a need for requests the trend, e, of the load needs to be rising, otherwise unnecessary reductions might be requested. To respond promptly to changes of the heat load and to identify the trend of the load, an Exponentially Weighted Moving Average (EWMA) is used. The EWMA, e, is applying a percentage of the current load to the previous moving average load, i.e., the EWMA place more weight on recent values.

\subsection{Cluster Agent}

On request from the producer agent the cluster agent calculates the cost for implementing a reduction of a certain percentage in 
the cluster. The calculation is performed by issuing requests to the consumer agents within its cluster to calculate their costs to take on the restriction. It then selects the best bids from the consumer agents and return a concatenated bid to the producer. If the cluster is selected by the producer the cluster agent informs the correct consumer agents that they are to reduce their consumption. The general idea with the cluster is to divide and conquer, i.e, instead of a large market at the producer we use a number of smaller markets. In this way we maintain local information, e.g., which agents populates a certain area, and makes the problem of choosing substations easier for the producer. The cluster agent is also responsible to make sure that restrictions are implemented, e.g., if the environment for a consumer agent (that is supposed to take on a restriction) changes beyond the model of the consumer agent. The cluster agent needs to find another agent within its cluster to take on the restriction. If it fails to find another consumer agent, it informs the producer that the restriction failed. Finally, another task for the cluster agent is to estimate the current consumption within the cluster and inform the producer of this at regular intervals.

\section{DEPLOYED SYSTEM}

The area where the agent system is installed is composed of 14 buildings with a total of 350 apartments. The district heating network for the area is very favorable since it can be seen as a separate part of the network in the town, see Figure 5. We were thus able to monitor the total delivered energy to the area for verification purposes. To monitor the energy delivered to the area we installed a clamp-on flow meter on the pipe at the entrance to the area, close to the PC building.

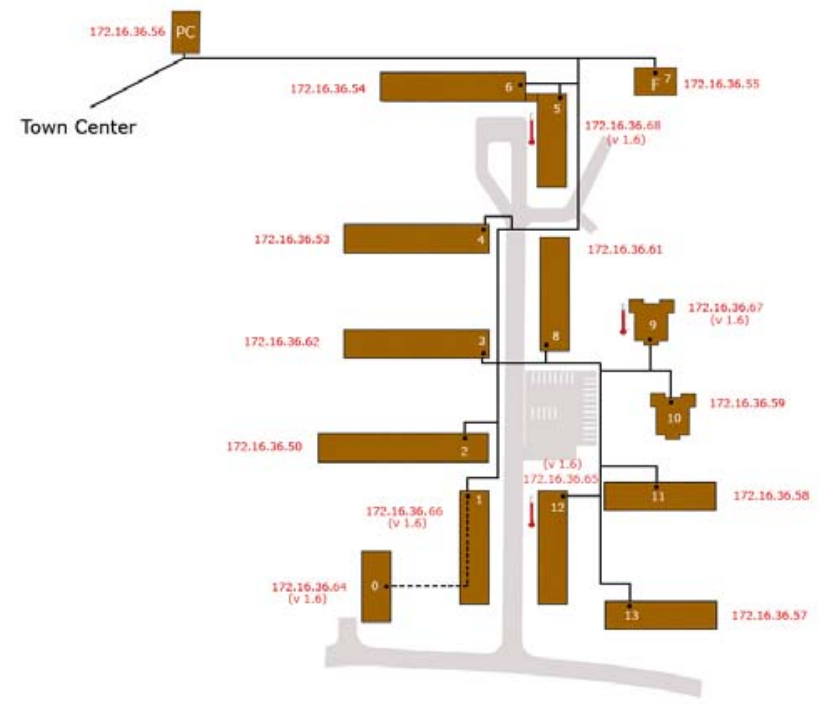

Figure 5. Connected buildings

The PC building, a separate heating station, is not included in the agent society and within this context only act as the flow meter node. Ten of the buildings are buildings with three floors, two are buildings with seven floors and one is a building with six floors. The last building, F, is a service building without apartments which is closed and empty of personnel during night time. Each building is controlled by one agent. The inhabitants of the area represent a broad variation including families with children, elderly, students etc.

We also installed three separate temperature meters to measure the indoor temperature in buildings 5, 9 and 12. In excess we also instructed the landlord to record any complaints on indoor temperature.

\subsection{Result}

The system automatically controls and monitors the amount of delivered energy in the area. All buildings take part on the economic market for reductions through their agents.

In Figure 6 we show that the largest amount of reductions are concentrated to the hours of the day when hot tapwater is most frequently used, i.e., in the morning and early evening.

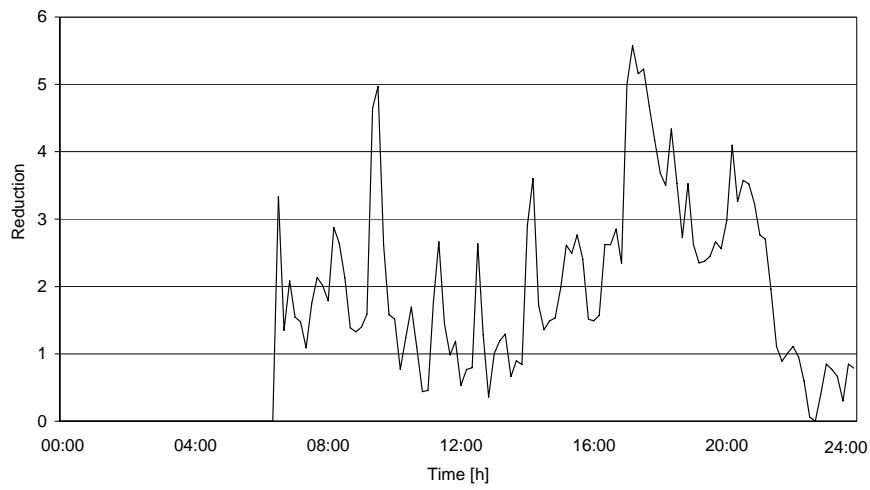

Figure 6. Reductions

In Figure 7 we show the difference in delivered energy (in terms of temperature difference) between the system with and without agents. Every second that we reduce the gradient between the temperatures will result in less energy consumed.

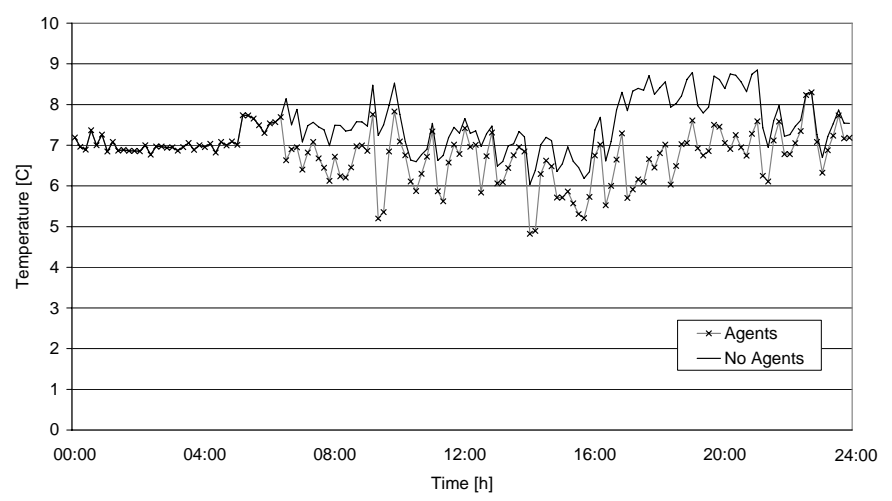

Figure 7. Difference in delivered energy

If we look at how the reductions are divided between the buildings we can identify three characteristics; the reductions are spread over basically all buildings, the reductions are very short in time and there are quite a number of reductions during a day. 
This is not something that is statically decided at design time, but instead something that dynamically arises from the usage of an economic market and the utility functions. This is a result of the agent society continually adjusting and adapting to its surroundings in order to find the path of least resistance, i.e., where the cost for reduction is lowest at any point in time.

In Figure 8 we show the implemented reductions for four different buildings, F, 1, 2, and 3 . We can se that different buildings are reduced at various times and by different amounts. Also, the robustness of the system is shown by the agent that hasn't participated at all in the evening. The reason for not participating can either be that the building is in the shadow and thereby a bit cooler than the ones in the sun or that the network connection or agent is down. Even though the result is likely to be better the more buildings that participate we show that the system still works when some of the agents, for whatever reason, fail to engage in the economic auction. Also, in the lower graph in Figure 8 we show the reductions implemented in the service building. Since this building does not have any apartments we configured the agent to bid a bit more generous resulting in more reductions.
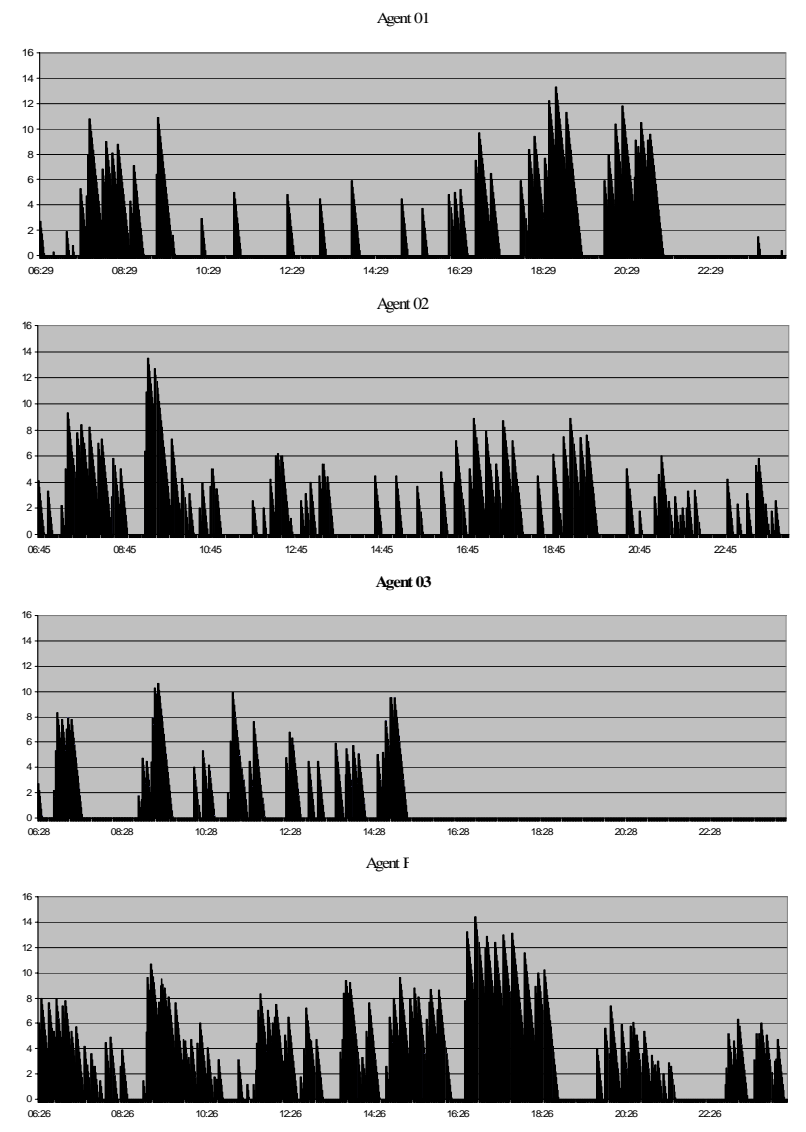

Figure 8. Reductions awarded to different agents

During operation we could not detect any reduction of indoor temperature what so ever. Also, there were no complaints from the people living in the area. The people living in the area where not informed that the system was running.
The results from the system show that there exists a considerable thermal buffer within the buildings and that this buffer can be used for DSM strategies. Also, the system shows that the effect is enhanced by coordinated actions between the agents.

\subsection{Return of Investment}

During field-test we showed that the system can reduce the total energy consumption in the area by $4 \%$ which corresponds to 78500 Swedish crowns per year for the area (approximately $\$ 11$ 100).

We have calculated from the field-test that the full potential of the system will result to savings of more than $10 \%$ of the total energy consumption, depending on the characteristics of the buildings. During our field-tests we only used about $1 / 4$ of the available thermal buffer. For the area in question this would mean savings of approximately 235000 Swedish crowns a year (approximately $\$ 33200$ ). Given that the system only has to cover its own investment costs, since the HES normally covers its own costs, the system gives full return of investment within the first year.

\subsection{Discussion}

The results from the field-tests show a clear profit for the estate owners, since we reduce the amount of energy consumed. At the same time we argue that the operators of the district heating systems will benefit from the system. At first this might seem contradictory but there are several system wide benefits with DSM which more than compensates the operators for the reduced energy sale. For example, the flow balancing that we showed in the field-tests would in the long run offer the operators a possibility to handle flow and capacity problems in different parts of the network. This is an important issue since much of the core of today networks were built during the 60 s and 70s without any possibility to foresee the enormous expansion of many district heating systems during resent years. Another example is operators who have low availability of base load production and are forced to use fossil fuel as a production source for energy during peak loads. There are obvious major economical and environmental benefits in reducing the use of these peak load burners.

\section{CONCLUSIONS}

A DHS without an overall control system is basically composed of a number of completely selfish and autonomous units, i.e., substations, working only to satisfy their own local goals (sufficient domestic hot tap water and indoor temperature) without any consideration whatsoever about the overall efficiency of the system or the state of other units in the network. We have introduced a level of automatic system control by using a semidistributed MAS architecture to show the value of cooperation among HES in DHS.

In this paper we have shown that the value of a large number of small local decisions taken all in all has a great impact of the overall system performance. The system described in this paper does not consider load shifting, only peak cutting, i.e. where the total energy delivered is not the same with agents as without them.

However, the results in this paper indicate that it is possible to remove $10 \%$ of the heating load without affecting the QoS delivered. The results also indicate that it is possible to extend the 
number of customers in an existing DHS without the need of increasing the production capacity.

All DHS are more or less unique when considering specific details of inhabitant preferences, household equipment, size etc. This, of course, complicate matters when about to draw general conclusions from a single installation. However, we have shown that there are clear benefits of DSM in DHS and that it is a viable approach to address the over all system control with a MAS.

The principle of DSM works when the total system utility is more important than the individual, i.e., there is a need of partial global responsibility from the customers. This responsibility could be created both by economic incentives as well as by environmental incentives. The picture is not clear whether customers will accept reductions without economic compensation or not. In reports regarding the electricity market it has been stated that it is a necessity to compensate customers otherwise they will not participate [15] and that there in Sweden today is no incentive for individual customers to save energy during peak hours since tariffs are constant during the day [16]. However, there are also reports indicating that customers are interested in saving the planet for free as well [17].

It is worth noting that the project has also given rise to a spin-off research project dealing with the intricacies of simulating the dynamics within a DHS [18]. It was necessary to develop this simulator in order to validate the DSM strategy before it was applied in a real DHS with real customers and producers.

\section{FUTURE WORK}

We will in future experiments focus on developing load-shifting strategies for the MAS, i.e., not only reducing the load but also moving the load in time. We will also perform studies on primary return temperatures to investigate if it is possible to develop strategies for the MAS to reduce the return temperatures thus facilitating an increased efficiency in the use of CHP production. Future work also include studies on differential tariffs in DHS as well as investigations of possible approaches to a complete market-oriented approach to the management of DHS where producers are competing and where there is third-party access.

Controlling the load has potentially major benefits to CHP production and it would be interesting to connect the load controlling strategies to, e.g., the energy prices at Nord Pool (The Nordic Power Exchange).

\section{ACKNOWLEDGMENTS}

This project has been supported by VINNOVA and was a collaboration between NODA, Blekinge Institute of Technology and Alfa Laval. The effort in commercialising the system has been supported by Karlshamnsbostäder, Karlshamns Energi, Sparbanken i Karlshamn and Blekinge Business Incubator.

\section{REFERENCES}

[1] Österlind, B., "Effektbegränsning av fjärrvärme", Rapport 63:1982, Byggforskningsrådet, ISBN 91-540-3714, 1982 (in Swedish)

[2] Andersen, K.K., and Poulsen, H., "Building Integrated Heating Systems", in Proceedings of Building Simulation, Volume 1 pp.105-112, Kyoto, Japan, 1999.
[3] Österlind, B., "Avläsnings- och kontrollsystem för fjärrvärmenät", Rapport 85:1990, Byggforskningsrådet, ISBN 91-540-5254-8, 1990 (in Swedish)

[4] Drysdale, A., and Stang, J., "Optimised DH systems using remote heat meter communication and control", in Proceedings of the 8th International Symposium on District Heating and Cooling, Trondheim, 2002.

[5] LIPAedge, retrived 2005-08-10, http://www.lipower.org/cei/lipaedge.html

[6] Levin, P., and Wesslen, M., "Laststyrning i småhus med vattenburen elvärme", Vattenfall Energimarknad, 1993 (in Swedish)

[7] Johansson, P., and Ejeklint, L., "Laststyrning av direktverkande villor i Boden", Uppdrag 2000, Luleå, 1991 (in Swedish)

[8] Aune, M., "Energy Technology and Everyday Life - The domestication of Ebox in Norwegian households", in Proceedings of ECEE Summer Study, 2001.

[9] Nordvik, H., and Lund, PE., "How to achieve energy efficient actions as an alternative to grid reinforcement", in Proceedings of ECEEE Summer Study, 2003.

[10] Johansson P.O., "Laststyrning i småhus - Fallstudie hos Skånska energi AB", MsC, LUTMDN/TMHP-03/5025-SE, 2003 (in Swedish)

[11] IEA District Heating and Cooling., "Optimised District Heating systems using remote heat meter communication and control", Annex VI report, ISBN 90-5748-027-1, 2002.

[12] Sipilä, Kari., and Kärkkäinen, Seppo., "Demand side management in district heating systems", Euroheat \& Power - Fernwärme international, Vol. 3 pp. 36 - 45, 2000.

[13] Noren, C., and Pyrko, J., "Laststyrning i lokaler datorsimulering", issn 0282-1990, LTH, 1998 (in Swedish)

[14] Bøhm, B., Lucht, M., Park, Y., Sipilä, K., Ha, S., Won-tae, K., Bong-kyun, K., Koljonen, T., Larsen, H., Wigbels, M., Wistbacka, M., "Simple models for operational optimisation”, Report 2002:S1, NOVEM, ISBN 90-5748021-2, 2002.

[15] Energimyndigheten, "Flexibiliteten på elmarknadens efterfrågesida - hur kan potentialen hos små elanvändare aktiveras ?", Underlag för Svenska Kraftnäts utredning om effektbalansen, 2002 (in Swedish)

[16] Österman, E., "Remissyttrande over statens energimyndighets rapport: Månadsvis avläsning av elmätare", Slutredovisning av regeringsuppdrag, Villaägarnas riksförbund, retrived 2005-10-10 http://www.villariks.se/filer/remiss_021029.pdf, 5/7-2005 (in Swedish)

[17] Pyrko, J., Sernhed, H., and Abaravicius, J., "Hushållen klarar avstängd el", Energivärlden, 1:2005, Energimyndigheten, 2005 (in Swedish)

[18] Wernstedt, F., "Multi-Agent Systems for District Heating Management", PhD Thesis, Blekinge Institute of Technology, 2005. 